\title{
Influence of natural dairy probiotics on health
}

\author{
Natalia Wojciechowska-Alwin ${ }^{1, A-D, F \oplus}$, Dominika Sikora ${ }^{1, A-D, F \oplus}{ }^{\text {, Adam Lipski }}{ }^{2, D, F} \oplus$, \\ Damian Skrypnik ${ }^{3, A, D-F(}$
}

${ }^{1}$ Student Scientific Club of Clinical Dietetics, Department of Treatment of Obesity, Metabolic Disorders and Clinical
Dietetics, Faculty of Medical Sciences, Poznan University of Medical Sciences, Poznan, Poland

${ }^{2}$ Department and Clinic of Urology and Oncological Urology, Poznan University of Medical Sciences, Poznan, Poland

${ }^{3}$ Department of Treatment of Obesity, Metabolic Disorders and Clinical Dietetics, Poznan University of Medical Sciences, Poznan, Poland

A - Research concept and design, B - Collection and/or assembly of data, C - Data analysis and interpretation,

$D$ - Writing the article, E-Critical revision of the article, F- Final approval of article Wojciechowska-Alwin N, Sikora D, Lipski A, Skrypnik D. The influence of natural dairy probiotics on health. J Pre-Clin Clin Res. 2019; 13(4):
153-161. DOI: $10.26444 /$ jpccr/115441

\section{Abstract}

Introduction. Probiotics are live microorganisms which, administered in appropriate amounts, have a beneficial effect on human health. Food products that contain these microorganisms are known as natural probiotics. Probiotic food include the group of dairy products in which fermented milk products are majority.

Objective. The aim of the study is to review current data and summarize knowledge on the effects of consumption of dairy probiotics on human health. The review also aims at discussing the potential of these health-supporting microorganisms as a prevention factor against civilization diseases.

State of knowledge. Consumption of probiotic food, especially natural dairy probiotic food, may have a positive effect on health due to the presence of probiotic bacteria or by the presence of their metabolites (postbiotics) demonstrating bioactive effects. The intake of these products is associated with the improvement of parameters such as lipid profile, insulin sensitivity, cardiovascular risk parameters, or presents protective effect on bones. Studies show a correlation between the consumption of natural probiotics and reduction in duration of diarrhea or alleviation of the course of inflammatory bowel diseases.

Conclusion. The influence of natural dairy probiotics consumption on the state of health has recently been broadly investigated. Regular consumption of these products has shown beneficial effect on gut microbiota and on a wide range of health parameters. However, further studies are necessary to draw a precise conclusion.

\section{Key words}

probiotics, gastrointestinal microbiota, diet, dairy products, cultured milk products

\section{Abbreviations}

ACE - Angiotensin-Converting Enzyme; ASD - Autism Spectrum Disorders; CFU - Colony Forming Units; CLA - Conjugated Linoleic Acid; DNA - Deoxyribonucleic Acid; EPS - Exopolysaccharides; FAO - Food and Agriculture Organization of the United Nations; GABA - y-Aminobutyric Acid; Glu - Glutamic Acid; HDL - High Density Lipoprotein; IBD - Inflammatory Bowel Diseases; IBS - Irritable Bowel Syndrome; LDL - Low Density Lipoprotein; LPS - Lipopolysaccharides; MS - Multiple Sclerosis; SCFA - Short-Chain Fatty Acids; PD - Parkinson's Disease; WHO - World Health Organization; WPC - Whey Protein Concentrate

\section{INTRODUCTION}

Intestinal microbiota. Human gastrointestinal microbiota is an unique ecosystem residing in the intestines and consisting of microorganisms such as bacteria and fungi $[1,2]$. It is estimated that this ecosystem contains 1,500 bacterial species [1]. The ratio of bacteria to cells in human body is $1: 1$, rather than 10:1 as established previously [3]. Intestinal microbiota include such bacteria as Lactobacillus spp., Streptococcus spp. in the duodenum, Escherichia coli in the jejunum, Bacteroides spp., Enterococcus spp. in the ileum, anaerobic bacteria, e.g. Bifidobacterium bifidum, Lactobacillus spp., Clostridium septicum, Prevotella spp. and facultatively anaerobic or

Address for correspondence: Natalia Wojciechowska-Alwin, Student Scientific Club of Clinical Dietetics, Department of Treatment of Obesity, Metabolic Disorders and Clinical Dietetics, Faculty of Medical Sciences, University of Medical Sciences, Szamarzewskiego 82/84, 60-569, Poznan, Poland

E-mail: nataliawojciechowska.1997@gmail.com

Received: 28.10.2019; accepted: 18.12.2019; first published: 31.12 .2019 aerobic bacteria, e.g. Enterobacter spp., Klebsiella spp., Staphylococcus spp., Pseudomonas spp. in the large intestine [1]. The large intestine is the area where the largest number of microorganisms is found [2]. Composition of the intestinal microbiota is unique. Some researchers hypothesize that its profile could be developed during prenatal life. In the uterus there is a range of health-promoting bacteria (Proteobacteria, Bacteroidetes, Fusobacteria, Actinobacteria), microorganisms' DNA (deoxyribonucleic acid) of microbiota and its metabolites, such as short-chain fatty acids (SCFA) [4]. Studies on mice have proved that the environment of the uterus effects on the formation of the immune system of offspring. Administration of Acinetobacter lwoffii and Lactobacillus rhamnosus during pregnancy in mice led to mild allergy reaction in the offspring. However, no immunomodulatory effect of the uterus environment in the prenatal period has been confirmed in humans [4], although the health effects of vaginal childbirth have been proven. In children born through vaginal delivery, a more 
diverse intestinal microbiota was found compared to that in caesarean section [4]. Breastfeeding helps to colonize the digestive tract with Bifidobacterium spp. and Lactobacillus spp. bacteria, the fermentation products of which prevent the colonization of pathogenic bacteria. Breast milk also includes prebiotics (oligosaccharides), IgA-class antibodies, cytokines and anti-inflammatory agents [5].

The formed profile of gut microorganisms is a part of the homeostasis of the organism. Some bacteria of microbiota have pathogenic properties (some strains of Staphylococcus spp. and Clostridium spp.), but in physiological conditions these bacteria are in biological balance and do not constitute a danger to health $[1,5,6]$. It is suspected that dysbiosis (quantitative and qualitative disturbances in the composition of the microbiota) and the presence of pathogenic strains may predisrelate? to the occurrence of civilization diseases, obesity, autoimmune disorders, or inflammatory bowel syndrome (e.g. Crohn's disease, ulcerative colitis) $[1,5,6]$.

Intestinal microbiota is primarily responsible for metabolic function and participates in the decomposition and digestion of nutrients present in the intestinal lumen $[2,7]$. The intestinal microbiota is also responsible for proper mineral balance [7]. Absorption, bioavailability and storage of mineral components is regulated, to a certain extent, by specific strains of bacteria [7]. The microbiotamineral interdependence system has been confirmed in animal models or in vitro for such elements as iron, calcium, magnesium, zinc, selenium and copper [7]. Microbiota is also responsible for the synthesis of some vitamins (B and K) [2]. It produces glutamic acid (GLU) which indirectly effects on the level of $\gamma$-aminobutyric acid (GABA), serotonin and other neurotransmitters [8]. It promotes lipid balance through the production of hydrolase, thus affecting the metabolism of fat in the liver. In addition, it presents a trophic function, nourishing and protecting the intestinal epithelium. Microbiota stimulates the production of mucin, which forms a mucous layer constituting an intestinal barrier for toxins and harmful microorganisms [1].

Intestinal microbiota performs an immune function by creating a selectively permeable intestinal barrier [9]. It also exerts an influence on the development of immunotolerance or the formation of T lymphocytes [9]. The nervous system and intestinal microbiota form a functional gut-brain axis. Microbiota, producing neuroactive substances, has both a direct and indirect effect on the structure and functioning of the brain; by the production of neurotransmitter, microbiota can control stress-related behaviours, memory, learning and other cognitive functions [9]. A number of studies are currently being performed to determine the mechanisms of interaction of the intestinal microbiota and the central nervous system [9].

Intestinal microbiota, like all other structures of the body, is exposed to many exo- and endogenous factors. Stimuli such as antibiotic therapy, diet, age, intestinal peristalsis or excessive hygienization disturb the balance of this unique system [1]. However, some time after the adverse stimulus stops, the intestinal microbiota spontaneously returns to homeostasis [6]. The most dynamic changes in microbiota structure occur after exposition on nutrients and pharmaceuticals [8]. It is believed that the restoration of intestinal microbiota after antibiotic therapy lasts from a few months to even a few years [5].
The role of the intestinal microbiota is still not fully understood. Current reports indicate that it has a significant impact on the functioning of the whole organism. Abnormalities in its composition correlate with the appearance and severity of many diseases. It seems, that the use of appropriate probiotic therapy could result in a reduction in disease severity, or even be a part of primary prophylaxis $[2,8]$.

Natural probiotic products have been known since ancient times. The ancient Greeks, Romans and Egyptians knew about and consumed the food produced as a result of fermentation [10], and an increasing interest in research into natural probiotic foods has been observed since the beginning of the 20th century [10]. Élie Metchnikoff, one of the pioneers in the research on probiotic who was, awarded the Nobel Prize in medicine in 1908 for his work in the field of immunology, as described in the book The Prolongation of Life. Optimistic Studies, which describes that huge amounts of lactic acid bacteria are supplied to the digestive tract by the consumption of food subjected to fermentation (curdled milk, kefir - fermented milk, cucumbers and sauerkraut) [10]. Metchnikoff was probably the first person who claimed that health could be enhanced by food probiotics [11]. He created the concept of positive function of microorganisms and the beneficial role of natural probiotics [11]. This initiated an avalanche of research work on probiotic products. Currently, a wide range of probiotic products with various properties are available on the food market.

The aim of this review is to present the current knowledge on natural dairy probiotics as a factor significantly modifying the quality and function of gut microbiota and influencing the state of health.

Probiotics - definition and characterization. The word probiotic (Gr. pro bios - for life) was probably used for the first time by Ferdinand Vergina in 1954 in the publication Anti-und Probiotika [12], which showed the antagonism of probiotics to antibiotics. In 1965, Lilly and Stillwell [13] attempted to define the term 'probiotics' as microorganisms that stimulate the growth of other microorganisms. In the following years, this definition has been changed and modified many times [10]. The current definition of probiotics was developed in 2002 by experts of the FAO/WHO (Food and Agriculture Organization of the United Nations/World Health Organization) [14]. According to this definition, probiotics are live microorganisms which, administered in appropriate amounts, have a beneficial effect on human health [14]. These are microorganisms, mainly bacteria, which must be classified according to specific species, types and strains [15]. The properties and characteristics of probiotics are not described for each types or species, but only for specifically selected strains [10].

A strain may be called a probiotic when it meets the conditions for safety, functionality and technological utility [10]. The safety criteria include: human or animal origin, isolation from the gastrointestinal tract of healthy subjects, demonstration of history of safe use, precise identification of phenotypic and genotypic characteristics, no data showing association of strains with infectious diseases, no ability to bile acid splitting, no antibiotic resistance gene located on unstable genetic elements and no side-effects associated with application [10]. The functional criteria are designed to ensure the survival of probiotics in the gastrointestinal 
tract and reaching the colon where probiotics can present its functions. For this reason, the strain should be resistant to the acidic environment of the stomach, bile salts, bactericocytes and acids produced by the endogenous gastrointestinal tract microbiota [10]. In addition, it should be competitive with endogenous microbiota and with closely related species, has survival ability, metabolic and growth activity at the destination, antagonistic activity to pathogens, and adhere to and be able to colonize specific destinations in the body [10]. Technological usefulness of probiotics is associated with genetic stability, resistance to bacteriophages, ease of production of large amounts of biomass, viability and durability of the desired characteristics of probiotic strains during preparation and distribution, high survivability during storage, and desired sensory properties of finished products [10].

Probiotics have a positive effect on health, therefore, their use is very wide. Probiotics are recommended during and after antibiotic therapy to restore the body's natural microbiota, in assisting the digestive processes, absorption of vitamins and nutrients, as well as to help treat foot allergies [16]. Probiotics are also used to assist in the treatmen' of many diseases. Probiotics are used as additions to functional foods (i.e. foods that in addition to the nutritional function have scientifically proven beneficial effects on health' [15]) and food preservation [16].

The beneficial effects of individual probiotic strains have been confirmed by numerous clinical studies. Examples of probiotics supporting obesity treatment are Lactobacillus gasseri SBT2055 and Lactobacillus plantarum, for which the ability to reduce weight and arterial blood pressure was demonstrated in obese patients [10]. The use of Lactobacillus acidophilus La5, Bifidobacterium lactis $\mathrm{Bb} 12$ in patients with diabetes mellitus type 2 has reduced total cholesterol and LDL (low density lipoprotein) cholesterol levels [10]. Another example is the supplementation of B. bifidum, B. lactis and Lactococcus lactis in 156 mothers of infants at high risk of eczema, which resulted in the reduction of the symptoms of the disease in infants [10]. In the study by Hertzler and Clancy the concomitant use for one day of L. lactis, Lactobacillus plantarum, Streptococcus cremoris, Lactobacillus casei, Streptococcus diacetylactis, Saccharomyces florentinus and Lactococcus cremoris improved the tolerance and digestibility of lactose in people with impaired lactose digestion [10]. Probiotic have shown beneficial properties in obese patients [17]. Obese postmenopausal women supplementing a probiotic preparation for 12 weeks had improved parameters, such as waist circumference, body fat mass, amount of subcutaneous fat, as well as the lipid profile and carbohydrate metabolism [17]. In addition, a positive effect was found of the probiotic on uric acid and glucose levels [17]. A similar study demonstrated the effects of multistrain probiotics on cardiovascular function [18].

Natural probiotics. Natural probiotics are food products naturally containing one or more probiotic strains [10]. A product may be called probiotic when it contains a minimum of $10^{6}$ active bacterial cells per milliliter [16]. Probiotic food owes the presence of probiotics to the production processes or the addition of selected probiotic strains by manufacturers [16]. Probiotic bacteria are introduced into food products in three ways - by adding lyophilized bacterial cultures in the form of a vaccine of attenuated microorganisms, or in the form of a pharmaceutical substance. The correct way is selected based on several factors, including: product type, consistency, and further technological processes [19].

Probiotic foods include mainly fermented dairy products, vegetables and fruits subjected to the process of fermentation, as well as fermented sausages, cakes, sourdough bread, beer or wine [16]. The presence of probiotic strains, in addition to potential health properties, gives food a specific taste and smell and protects against the development of pathogenic microorganisms [16].

Fermented dairy products. Microorganisms occur in dairy products due to their natural presence resulting from the production process or as an additive in order to receive a product with the desired properties [20]. Fermented dairy products, such as natural yoghurt, buttermilk and kefir, are very popular. They are often recognized by consumers as health-promoting. Recently, the amount of research on their effects on the human body has increased significantly. Consumption of fermented dairy products may have a positive effect on health due to the presence of probiotic bacteria or by the presence of their metabolites (postbiotics) demonstrating bioactive effects [20].

Probiotic strains found in fermented dairy products include primarily lactic acid bacteria. These include mainly the following species of the genus Lactobacillus: $L$. acidophilus, L. brevis, L. bulgaricus, L. fermentum, L. gasseri, L. delbrueckii, L. helveticus, L. anglerfish, L. cellebiosus, L. (para)casei, L. plantarum, L. reutri, L. rhamnosus, L. salivarius, as well as species of the genus Bifidobacterium: $B$. animalis, B. infantis, B. lactis, B. bifidium, B. breve, $B$. longum, B. termophilum, B. adalescentis [20, 21]. Some products also include other species, such as L. cremoris, Lactococcus diacetilactis, Streptococcus lactis, Streptococcus thermophillus, Streptococcus intermedium, Bacillus coagulants, Bacillus subtilis, Bacillus licheniformis, Bacillus pumilus, Bacillus lentus, Propionibacterium freudereichii subsp. shermanii, Leuconostoc mesenteroides, Bacteriodes ruminicola, Bacteriodes capillus, Bacteriodes amylophilus, Bacteriodes suis, as well as the yeast Saccharomyces cerevisiae and Candida glabrata and the moulds Aspergillus niger and Aspergillus oryzae [21].

Yogurt is one of the most popular and at the same time wellinvestigated dairy products containing probiotic bacteria. The probiotic strains found commonly in natural yogurts are $S$. thermophilus and $L$. delbrueckii subsp. bulgaricus in the amount of $10^{4}-10^{9}$ colony forming units per gram (CFU/g) or colony forming units per milliliter (CFU/ml) [22]. The frequent occurrence of Bifidobacterium spp. and Lactobacillus spp. is also observed; however, their numbers have much larger fluctuations and ranges from undetectably low to $10^{8} \mathrm{CFU} / \mathrm{g}$ [22]. In some natural yogurts, the addition of specific bacterial strains is used to obtain the desired technological, health or organoleptic characteristics [21]; these are: B. animalis spp. lactis BL 04, L. gasseri 4/13, L. rhamnosus GR-1 and L. rhamnosus RC-14 [21]. Rezac et al. compared probiotic bacteria composition in fresh and frozen yoghurt [22]. Similar results were found in the range of the amount of lactic acid bacteria in both products, as well as in the range of their survival, even when frozen yogurt was stored for one year at temperature $-23^{\circ} \mathrm{C}$ [22].

In other fermented dairy products, such as kefir, curdled milk or butternut, the amount of lactic acid bacteria varies 
from $10^{5}-10^{9} \mathrm{CFU} / \mathrm{g}$ [22]. The presence and amount of bacteria in the product is determined by the type, region of origin, and the manufacturer [22].

Impact on metabolic syndrome. It is suggested that a diet rich in dairy products, particularly in natural yogurt, can bring many health benefits. It has been proven that the consumption of high-fat and skimmed yogurt, as well as milk and other skimmed dairy products, reduces the risk of metabolic syndrome in the Mediterranean population at high risk of cardiovascular disease [23]. However, another study in Spain showed that the consumption of natural yoghurt, both high-fat and skimmed, did not have an influence on the development of metabolic syndrome, except from central obesity [24]. In addition, the opposite effect was noted of high yogurt intake while consumption of large amount of fruit for the development of metabolic syndrome [24].

Dairy products, in particular fermented products such as yogurt, are often recommended for patients consuming calorie-restricted diet. Madjd et al. compared the effect of consuming plain natural yogurt with reduced fat content (containing only the standard starter cultures of $S$. thermophilus and L. bulgaricus) with the effect of probiotic yogurt consumption (containing the traditional strains of $S$. thermophiles and L. bulgaricus and the addition of $B$. lactis BB12 and L. acidophilus LA5) in 89 women oa calorierestricted diet [24]. There were no significant differences in weight loss depending on the yogurt used. Increased insulin sensitivity and beneficial lipid profile parameters were observed in women using yogurt containing probiotics [25]. Research conducted by Mohammadi-Sartang et al. compared the effect of the intake of yogurt enriched in protein, vitamin $\mathrm{D}$, calcium, prebiotics and probiotic strains (S. thermophilus, L. bulgaricus and $B$. lactis $\mathrm{Bb}-12$ in the amout of $10^{7} \mathrm{CFU} / \mathrm{g}$ ) with consumption of plain low-fat yogurt (containing only S. thermophilus and L. bulgaricus) on the effectiveness of weight reduction in patients with metabolic syndrome [26]. There were no significant differences in weight loss depending on the yogurt consumed. However, the beneficial effect of enriched yogurt on insulin response, HDL (high density lipoprotein) cholesterol and triglyceride serum levels and body composition was demonstrated [26]. These studies suggest that, despite the absence of a significant difference in weight reduction, the use of a dairy product with probiotic strains has a positive effect on metabolic parameters, such as lipid profile and insulin sensitivity $[25,26]$.

Effects on the risk of cardiovascular events. A metaanalysis of nine cohort studies showed no significant effect of consumption of small amounts of natural yogurt, as well as other fermented dairy products, on reduction of the risk of cardiovascular incidents [27]. Only daily consumption of at least $200 \mathrm{~g}$ significantly reduced this risk [27]. A similar metaanalysis was carried out by Zhang et al., without giving a specific portion of a product, the intake of which is necessary to reduce cardiovascular risk [28]. Comparing 10 cohort studies, it was found that the consumption of fermented dairy products had a beneficial effect on the occurrence of cardiovascular incidents [28]. It is believed that this is the effect of the probiotic strains contained in yogurt and other dairy products with lactic acid bacteria on the reduction of excessive body mass by supporting the proper functioning of the intestinal microbiota [27]. In addition, probiotics affect other functions of the microbiota leading to improvement of intestinal mucosa, enhancement of host immunity, reduction of the production of inflammatory mediators. Moreover, probiotics affect the production of cytokines important for decrease in the risk of cardiovascular disease [28]. However, the authors emphasize the need for further research in this area $[27,28]$.

Effects on the mineral balance. Milk and fermented dairy products are not only a source of probiotics, but also of proteins and minerals such as calcium, phosphorus and zinc [29]. The supply of these elements is crucial for mineral balance. Many studies have shown a connection between the consumption of dairy products containing probiotic bacteria and bone mineral density [29]. Sahani et al. carried out a 12-year observation, which aimed to assess the relationship between consumption of milk and its various products, and the bone mineral density of the hips and spine [30]. It was shown that milk and yogurt intake was associated with a higher mineral density of the hip bone, in particular the femoral trochanter, but did not affect the mineral density of the spine. In addition, a negative effect was observed of the consumption of cream on overall bone mineral density [30]. The study also showed a slight protective effect of the consumption of dairy products for hip fracture [30]. Biver et al. conducted a three-year observation on the consumption of dairy fermented products in postmenopausal women [31]. Reduced bone loss was found in women consuming fermented dairy products, regardless of calcium, protein or energy intake. This phenomenon was not observed in women consuming mainly milk or ripening cheeses [31]. Researchers suspect that the positive effects of fermented dairy products consumption may result from the presence of probiotics [31]. Another analysis carried out by Michaëlsson et al. revealed a relationship between consumption of milk, fermented dairy products, vegetables and fruits, and the occurrence of hip fractures [32]. During an observation lasting 22 years, 38,701 women were included, of whom 5,827 experienced hip fractures [32]. The highest fracture frequency occurred in groups with high milk consumption and low consumption of vegetables and fruits [32]. However, in all groups with high milk consumption, regardless of the amount of vegetables and fruits in the diet, there was a high frequency of hip fractures. No such correlations were reported for fermented dairy products [32]. The smallest frequency of fractures was observed in groups with a high consumption of vegetables and fruits and fermented dairy products [32]. The authors explain the advantage of fermented milk products over regular milk by the presence of probiotics having antiinflammatory, antioxidant and protective properties on the bone of the hips [32].

Dairy products are a source of many elements necessary for the proper functioning of the organism. Studies on the content of minerals, such as selenium, copper, zinc, chromium, manganese, magnesium and calcium in fermented dairy products do not show significant differences between products depending on the present microorganisms $[33,34]$. Comparing the use of traditional starter cultures $(L$. bulgaricus subsp. delbruickii and S. thermophilus) with the use of traditional starter cultures and additional probiotic strains (L. bulgaricus subsp. delbrueckii and S. thermophilus and various strains of bacteria of the genus Bifidobacterium spp., L. casei, L. fermentum, L. acidophilus) and yeasts, there were 
no significant differences registered in the content of each mineral in various fermented dairy products manufactured from cow milk or goat milk $[33,34]$. The results of the studies agreed that the diversity of probiotic microorganisms in these products does not affect the mineral content [33, 34].

Influence on cancer risk. Nutritional prophylaxis and proper nutrition in cancer prevention and treatment have recently focused the scientific effort of both researchers and clinicians. Therefore, attention was paid to probiotic bacteria found in fermented dairy products and their effects on prevention and supportive action in the treatment of cancer. The anti-cancer effects of probiotics has not been fully proven, but it is supposed that it may be associated with an improvement of intestinal microbiota function. $L$. acidophilus and B. bifidum are considered to be beneficial strains in the prevention of caner [35]. Studies have shown that consumption of fermented dairy products such as yogurt reduces the risk of colon cancer $[35,36]$. This correlation has not been demonstrated in analyses taking into account the general consumption of dairy products, including high-fat ones [35]. This can be explained by the adverse effects of fat-rich dairy products that increase the bile acid levels in the large intestine and increase the risk of colon cancer [35].

Faghfoori et al. showed that the probiotic bacteria found in fermented dairy products have the ability to reduce the expression of ErbB-2 and ErbB-3 genes [37]. Increased expression for ErbB-2 and ErbB-3 receptors is strongly correlated with the formation of colon cancer. Therefore, probiotics consumption has been shown to be prophylactic in the epigenetic mechanism [37]. In this study, the following probiotic strains were isolated from dairy products, mainly yoghurt and cheeses: L. casei, L. paracasei, L. plantarum, L. rhamnosus. It has been proved that their effect is associated with a reduction of proliferative activity of colon cancer cell lines HT-29 and Caco-2, and the aforementioned reduction in ErbB-2 and ErbB-3 gene expression [37]. The probiotic strain L. plantarum $17 \mathrm{C}$ has also been tested for antiproliferative activity by Haghshenas et al. [38]. In this study, its antitumour properties and ability to regulate apoptosis - a process significantly disturbed in neogenesis - have been proved [38]. Both studies showed that probiotic strains are not harmful to other body cells $[37,38]$.

Zhang et al. conducted a meta-analysis of 61 studies on the impact of the consumption of fermented dairy products on the risk of cancer [39]. It was shown that the consumption of these products reduces the risk of cancer of the colon, bladder and oesophagus [39]. In addition, it was proved that consumption of yogurt alone was also associated with a reduced risk of cancer of the colon and bladder [39]. However, it has also been shown that the consumption of fermented dairy products increases the risk of prostate and kidney cancer, but the mechanism of this phenomenon has not been explained [39].

Other health properties. Nowadays, various uses of probiotic strains in a range of diseases are explored in numerous scientific centres. Guillemard et al. proved that the supply of fermented dairy products containing the strain $L$. casei DN-114 001 reduce the duration of commonly occurring infectious diseases of the respiratory tract in the elderly population [40]. The beneficial effect of this probiotic on gastrointestinal infections was also noted, as well as the reduction in the duration of the diarrhea [40]. It is suspected that the mechanism of $L$. casei DN-114 001 influence is associated with the improvement of intestinal functioning and strengthening of the body's immune response [40]. Shadnoush et al. tested the effectiveness of probiotic yogurt in patients with inflammatory bowel disease during remission [41]. For this purpose, they used a natural yogurt $1.5 \%$ fat with the addition of $L$. acidophilus LA5 and $B$. animalis subsp. lactis BB-12 in the amount of not less than $10^{6} \mathrm{CFU} / \mathrm{g}$. It was shown that the consumption off probiotic yogurt for eight weeks increased the amount of bacteria Lactobacillus spp., Bifidobacterium spp., and decreased the amount of Bacteroides spp. in stool samples [41]. Changing the proportions of these bacteria can be beneficial and have a positive effect on bowel function. Thanks to this, the consumption of probiotic yogurt can help to alleviate the symptoms and the course of inflammatory bowel diseases, but further research is needed [41]. Bolla et al. conducted a study to check whether probiotic microorganisms can counteract the cytotoxic properties of Clostridium difficile [42]. The following probiotic microorganisms were isolated from kefir: Saccharomyces cerevisiae CIDCA 8112, Kluyveromyces marxianus CIDCA 8154, L. plantarum CIDCA 83114, L. kefir CIDCA 8348, L. lactis subsp. lactis CIDCA 8221. It was tested in vitro whether the use of single strains or mixtures thereof could neutralize toxins produced by the $C$. difficile [42]. The results of the study showed that only L. lactis subsp. lactis CIDCA 8221 was able to achieve this aim [42]. Clinical trials are needed to [rove the effectiveness of L. lactis subsp. lactis CIDCA 8221 in the treatment of C. difficile infection [42]. Agamennone et al. carried out a meta-analysis to show which products or dietary supplements may be used to prevent diarrhoea associated with antibiotic therapy [43]. In the dairy product category, only one fermented dairy product containing the probiotic bacteria $L$. casei DN-114001 in the amount of $10^{10} \mathrm{CFU} / \mathrm{g}$ showed its effectiveness [43]. These studies suggest that fermented dairy products may have a health-promoting effect in a variety of conditions. However, further analyses are needed to confirm the above properties and health-promoting effects of fermented dairy products in specific disease.

Non-fermented products. Cheese is a diverse group of products formed with the use of lactic acid bacteria. Some of the various species of Lactobacillus spp. and Bifidobacterium spp. have been noted in this group [20,44]. Probiotic bacteria, the presence of which is observed in various types of chees, are primarily: B. bifidum, B. lactis, L. acidophilus, L. casei, L. paracasei, and L. rhamnosus [45]. Moreover, in studies on cheese, the following strains of microorganisms have been observed: Pediococcus acidilactici CHOOZIT ${ }^{\mathrm{TM}}, \mathrm{L}$. rhamnosus GG, L. acidophilus LA5, Leuconostoc mesenteroide subsp. mesenteroides, Leuconostoc mesenteroide subsp. cremoris, L. lactis subsp. cremoris, L. lactis subsp. lactis, L. plantarum WHE92, Staphylococcus xylosus, Penicillium camemberti, Penicillium candidum, Brevibacterium lines, and Brevibacterium casei [20, 45-47]. The amount of the microorganisms is a very variable value and depends on many factors, and can be less than $10^{3}$ to $10^{9} \mathrm{CFU} / \mathrm{g}$, especially in ripening cheeses at some maturation stages [22, 45]. Microorganisms play an important role in the production of cheeses, they are the reason for the different tastes and smells of specific products (also tithin one species); their abnormal 
growth also carries a risk of certain sensory defects [45].

Emmental, or Swiss emental cheese, requies P. freudenreichii for production [48]. This strain is a technological starter for cheese, has a high survival rate and reaches up to about $10^{9}$ live bacterial cells per $1 \mathrm{~g}$ of mature cheese [48]. It is also a probiotic strain with health-promoting properties. It's supplementation has been proven to reduce inflammation of intestines or modify the composition of intestinal microbiota [48]. In addition, it has been shown that $P$. freudenreichii presents higher survivability in fermented dairy products than in lyophilized products [48]. Gagnaire et al. proved that the strain $P$. freudenreichii subsp. shermani CIRM BIA 1, which is present in the Emmentaler cheese, has a high resistance to the conditions of the gastrointestinal tract, which is important for maintaining probiotic properties in a final product [48]. The high stability of this strain creates the possibility to use Emmentaler as a natural probioti; however, this issue requires further research [48].

P. freudenreichii and Propionibacterium acidipropionici strains are also used in the production of other Swiss-type hard cheeses [49]. Rabah et al. confirmed the high survival of these strains supplemented in the form of dairy products in the human gastro-intestinal tract [49]. Its supply may result in a change of the composition of the intestinal microbiota leading to an increase in the amount of Bifidobacterium spp. and reduction in the quantity of Bacteroides spp.. However, the mechanism of this observation has not been explained although it is hypothesized that inflammation reduction plays the crucial role [49]. The study also revealed anti-cancer and anti-proliferative properties of these strains and their ability to produce short-chain fatty acids and conjugated fatty acid, which conduce apoptosis of cancerous cells [49].

The effect of the consumption of cheese and its probiotics on the metabolic syndrome has not been well investigated. Babio et al. showed that the consumption of cheeses is associated with a higher risk of developing metabolic syndrome than with the supply of other fermented dairy products, such as yogurt and skimmed milk [23]. The study included hard and rennet cheese, ricotta soft cheeses, grained cheese so-called 'rural' or French petit Swiss cheese. The authors explained this relationship by a higher content of fat, sodium, phosphorus, and overall higher calorie content of the cheeses. This study did not consider the presence of probiotic bacteria in these products [23].

Meta-analysis carried out by Zhang et al. concluded that the consumption of yogurt and cheese reduces the risk of cardiovascular events and diseases [28]. The authors emphasized the possible effects of probiotic bacteria on this relationship, especially Lactobacillus spp. and Bifidobacterium spp. [28]. Hütt et al. showed that the supply of L. plantarum (DSM 21380) in the amount of $10^{10} \mathrm{CFU} / \mathrm{g}$ with probiotic cheese ( $50 \mathrm{~g} /$ day) contributed to decrease in blood pressure, which is associated with lower risk of cardiovascular disease [50]. Also, a study on rats by Lollo et al. confirmed that consumption of probiotic cheese reduces blood pressure and further improves the lipid profile [51]. Minas Frescal, soft white cheese, popular in Spain and Brazil, at a dose of $20 \mathrm{~g}$ per day was used for this analysis. L. acidophilus LA $14, L$. lactis R-704 and B. longum BL 05 were used for its production, with each strain reaching approximately $10^{7} \mathrm{CFU} / \mathrm{g}$ [51]. The conclusions gave hope for the implementation of probiotic cheese in the prevention of cardiovascular diseases. In addition, Tognon et al. showed that the consumption of cheeses, as well as other fermented dairy products, is associated with a lower overall mortality; however, due to the limitations of the study, further analyses are needed to confirm this thesis [52].

Biver et al. in their three-year analysis of the consumption of fermented dairy products in postmenopausal women, reported reduced bone loss in patients consuming various fermented dairy products, with the exception of ripening cheeses [31]. This relationship has not been clarified [31]. Rizzoli and Biver observed that the consumption of fermented dairy products, including white soft cheeses, is associated with a lower risk of bone fractures [53].

Non-fermented dairy products include: mammalian milk, butter, ice cream, cream, whey protein, and other products made from unfermented milk [20], and are considered unconventional sources of probiotics [54]. The content of probiotic bacteria in unfermented dairy products varies and depends on many factors, including region of origin [55]. Joishy et al. observed the presence of bacteria from the genus Lactobacillus spp., Enterococcus spp., Lactococcus spp. and Leuconostoc spp. in raw non-pasteurized milk [55]. In heat-treated milk, they noted the presence of such species as: Aerococcus, Acinetobacter, Enhydrobacter, Chryseobacterium, Staphylococcus, Streptococcus, Jeotgalicus, Salinicoccus [55]. There are only a few studies that consider microorganisms found in unfermented dairy products and their impact on health. In addition, such products are often used as comparator in studies on the properties of probiotics and fermented milk products [56].

Postbiotics. Postbiotics are metabolites of microorganisms produced during the fermentation of lactic acid bacteria [20]. These substances include: enzymes, vitamins, EPS (exopolysaccharides), CLA (conjugated linoleic acid), bacteriocins, GABA and bioactive peptides [20]. Lactic acid bacteria produce mainly enzymes from the group of lipase and esterases [16]. Their presence in the gut effects in the alleviation of the symptoms of malabsorption and contributes to better digestive function [20].

Probiotic bacteria contribute to the production of many $B$ vitamins, including thiamine, folic acid and folate, biotin, riboflavin, and even cobalamin [20]. Studies show that probiotic microorganisms have the ability to produce various isomers of vitamins, also those absorbed by the human body. For example, L. plantarum CRL2130, B. longum B6 and B. infantis CCRC14633 strains from fermented soy drinks provide large amounts of vitamins B1 and B2, and $P$. freudenreichii bacteria in kefir increase the synthesis of vitamin B12 [20].

Bacterial postbiotics significantly influence intestinal microbiota and intestinal barrier tightness [20]. The use of EPS is associated with a positive effect on the growth of Bifidobacterium spp. bacteria, which contribute to improvement in the composition of gut microbiota and supportthe immune function of the body [20]. Strains such as $S$. thermophilus zlwTM11 derived from yogurt, $L$. plantarum YW11 from kefir or L. lactis SMQ-461 present in cheddar cheese, produce EPS contributing to the beneficial modification of the composition of the intestinal microbiota [20]. L. reuteri due to reuterin synthesis - a substance classified as a bacterocin, ameliorates gut microbiota composition [57].

Other properties of postbiotics are associated with the improvement of intestinal barrier function and alleviation 
of certain diseases. Cicenia et al. confirmed the protective effect of L. rhamnosus ATCC53103 metabolites on colon smooth muscle cells, preventing damage caused by lipopolysaccharides (LPS) [58]. These metabolites prevent intestinal motor disorders resulting from bacterial infection [58]. Gao et al. showed that protein HM0539 produced by L. rhamnosus GG protects the intestinal microbiome and its activity increasing mucin secretion, reducing intestinal permeability, and promoting the expression of proteins forming tight intestinal connections [59]. They also examined the effect of HM0539 on two diseases colitis and acute hepatic failure. In both cases, the use of this protein had a protective effect on the function of the intestinal barrier and alleviating the course of these diseases [59]. In addition, Han et al. have shown the preventive effect of $L$. rhamnosus GG protein metabolites against intestinal microbiom disorders caused by interferon- $\gamma$ in patients with IBS (irritable bowel syndrome) [60]. These effects, as in the previous study, are associated with the reduction of intestinal epithelial permeability and the continuity of the intestinal barrier through postbiotic activity [60]. Comapare et al. investigated the effect of the probiotic strain L. casei DG and its postbiotic on the modulation of the inflammatory response in patients with post-infectious IBS [61]. They proved that intestinal microbiota disorders are crucial in patients with irritable bowel syndrome, and the use of probiotics and postbiotics has a soothing effect on the course of the disease [61].

LAB contribute to the production of bacterocins postbiotics with antibiotic activity, contributing to the reduction of the risk of infection by same pathogens [16]. L. acidophilus bacteria produce acydophylline, lactacin and acidine, L. plantarum - plantacin, plantaricin S/K 83 and plantarricin A, L. reuteri - reuterin, L. sake - lactosin $\mathrm{S}$, saxacin A, bacteria of the genus Streptococcus - nisin [16]. Some researchers believe that postbiotics may have a protective effect on certain processes occurring in inflamed tissues and caused by some infectious factors, e.g. Salmonella spp. [62].

It has been proven that postbiotics contribute to lipid profile and blood pressure. L. rhamnosus C14, B. bifidum CRL1399, L. lactis LMG, L. acidophilus Lac1, and L. casei CRL431 from dairy products synthesize postbiotics which decrease lipid serum concentration [20]. Some peptic postbiotics, such as Ile-Pro-Pro (IPP) and Val-Pro-Pro (VPP) produced by the L. helvetius strain found in fermented dairy products, have shown anti-hypertensive effects resulting from the inhibition of ACE (Angiotensin-Converting Enzyme) [20]. In addition, some other bacterial species found in fermented dairy products, such as L. acidophilus, L. plantarum, L. delbrueckii subsp. bulgaricus, L. rhamnosus, S. thermophilus, L. lactis, also present an anti-hypertensive effect [57]. Another postbiotic decreasing blood pressure is GABA. This is a neurotransmitter in the central nervous system with multidirectional influence on the body and human health. GABA produced by $S$. thermophilus APC151 from natural yogurt, L. brevis OPY-1 and Streptococcus salivarius fmb5 present in fermented milk, exert hypoglycaemic and hypotensive effects [20].

Possible negative role of microbiota. Dysbiosis is a term for the imbalance in the diversity of microorganisms in gastrointestinal tract, which is usually associated with inflammation and defect in the intestinal barrier [63]. This disruptions of microbiota plays a role in the development of many diseases, such as obesity, IBD (inflammatory bowel diseases), IBS (irritable bowel syndrome), and some types of cancer [63]. Intestinal dysbiosis is also involved in the occurrence of such disturbances as autism spectrum disorders (ASD), multiple sclerosis (MS), Parkinson's disease (PD), schizophrenia and depression [8]. In people suffering from these diseases, the composition of the gut microbiota compared to healthy people differs significantly. Dysbiosis observed in ASD is associated with the intensity of behavioural disorders, in the case of MS it can be of significant importance in the etiopathogenesis of the disease, while in PD it is one of the factors determining the occurrence of symptoms [8].

It is still unknown whether microbiota imbalance is a cause or a consequence of many disorders [63]. The presence of some strains of microorganisms in gut microbiota are observed in specified diseases, such as the increase the number of conceivably proinflammatory Ruminococcus gnavus and Bacteroides spp. in IBD [63]. Moreover, patients with IBD often present an increased number of Veillonellaceae, Enterobacteriaceae, Pasteurellaceae, Fusobacteriaceae and lower amounts of Bacteroidales, Erysipelotrichales and Clostridiales [64]. Metabolism-related disorders are also associated with intestinal dysbiosis. In obesity, the reduction in abundance of Bacteroidetes and increased number of Firmicutes has confirmed in both animal and human models $[63,64]$.

Some strains of Clostridium spp. have potentially pathogenic properties, but in physiological conditions these bacteria are in homeostasis with other bacterial strains and organism of the host, and do not cause disorders [63]. C. difficile infection is a condition usually associated with diarrhoea after antibiotic therapy, which disrupts microbiota composition [65]. The association between intestinal dysbiosis and $C$. difficile infection is well proven [65] and is characterized by the reduction of Lachnospiraceae and Ruminococcaceae [63].

\section{CONCLUSIONS}

Dairy products are an abundant source of probiotic bacteria, and fermented milk products are the most precisely investigated type of natural dairy probiotics. There are a lot of data suggesting positive health effects associated with consumption of a dairy products containing probiotic bacteria. Regular intake can be a factor significantly modifying the quality and function of gut microbiota and influencing the state of health. However, there is still a need for further research investigating the content of microorganisms in dairy products, and the health effects of the consumption of natural milk probiotics.

\section{REFERENCES}

1. Krakowiak O, Nowak R. Mikroflora przewodu pokarmowego człowieka - znaczenie, rozwój, modyfikacje. Post Fitoter. 2015;3:193-200.

2. Karakuła-Juchnowicz H, Pankowicz H, Juchnowicz D, Valverde Piedra J, Małecka-Massalska T. Intestinal microbiota - a key to understanding the pathophysiology of anorexia nervosa? Psychiatr Pol. 2017;51(5):85970. https://doi.org/10.12740/PP/65308. 
3. Sender R, Fuchs S, Milo R. Revised estimates for the number of human and bacteria cells in the body. PLoS Biol [Internet]. 2016;14(8). https:// doi.org/10.1371/journal.pbio.1002533.

4. Jenmalm MC. The mother-offspring dyad: microbial transmission, immune interactions and allergy development. J Intern Med. 2017;282:484-95. https://doi.org/10.1111/joim.12652.

5. Jańczewska I, Domżalska-Popadiuk I. Kolonizacja przewodu pokarmowego noworodków oraz wpływ czynników modyfikujących mikrobiotę jelitową na zachowanie zdrowia. Forum zakażeń. 2016;7(6):443-8.

6. Gregorczyk-Maślanka K, Kurzawa R. Mikrobiota organizmu ludzkiego i jej wpływ na homeostazę immunologiczną - część I. Alerg Astma Immun. 2016;21(3):146-50.

7.Skrypnik K, Suliburska J. Association between the gut microbiota and mineral metabolism. J Sci Food Agric. 2018;98(7):2449-60. https://doi. org/10.1002/jsfa.8724.

8. Skonieczna-Żydecka K, Łnoiewski I, Maciejewska D, Marlicz W. Mikrobiota jelitowa i składniki pokarmowe jako determinanty funkcji układu nerwowego. Część I. Mikrobiota przewodu pokarmowego. Aktual Neurol. 2017;17(4):181-8. https://doi.org/10.15557/AN.2017.0020.

9. Cerdó T, García-Valdés L, Altmäe S, Ruíz A, Suárez A, Campoy C. Role of microbiota function during early life on child's neurodevelopment. Trends Food Sci Tech. 2016;57:273-88. https://doi.org/10.1016/j. tifs.2016.08.007.

10. Markowiak P, Śliżewska K. Effects of probiotics, prebiotics and synbiotics on human health. Nutrients. 2017;9(1021):1-30. https://doi. org/10.3390/nu9091021.

11. Mackowiak PA. Recycling Metchnikoff: Probiotics, the intestinal microbiome and the quest for long life. Front Public Health [Internet]. 2013;1:52. https://doi.org/10.3389/fpubh.2013.00052

12. Vergin F. Anti-und Probiotica. Hippokrates. 1954;25(4):116-9.

13. Lilly DM, Stillwell RH. Probiotics: Growth-promoting factors produced by microorganism. Science. 1965;147(3659):747-8.

14. Report of a Joint FAO/WHO. Working group on drafting guidelines for the evaluation of probiotics in food. London, Ontario, Canada: 2002. April, May. Guidelines for evaluation of probiotics in food.

15. Kapka-Skrzypczak L, Niedźwiecka J, Wojtyła A, Kruszewski M. Probiotyki i prebiotyki jako aktywny składnik żywności funkcjonalnej. Pediatr Edocrinol. 2012;18(2):79-83.

16. Mojka K. Probiotyki, prebiotyki i synbiotyki - charakterystyka i funkcje. Probl Hig Epidemiol. 2014;95(3):541-9.

17.Szulińska M, Łoniewski I, van Hemert S, Sobieska M, Bogdański P. Dose-dependent effects of multispecies probiotic supplementation on the lipopolysaccharide (LPS) level and cardiometabolic profile in obese postmenopausal women: A 12-week randomized clinical trial. Nutrients. 2018;10(6). https://doi.org/10.3390/nu10060773.

18. Szulińska M, Łoniewski I, Skrypnik K, Sobieska M, Korybalska K, Suliburska J, et al. Multispecies Probiotic Supplementation favorably affects vascular function and reduces arterial stiffness in obese postmenopausal women-A 12-week placebo-controlled and randomized clinical study. Nutrients. 2018;10(11). https://doi. org/10.3390/nu10111672.

19. Steinka I. Wybrane aspekty stosowania probiotyków. Ann Acad Med Gedan. 2011;41:97-108.

20. Linares DM, Gómez C, Renes E, Fresno JM, Tornadijo ME, Ross RP, et al. Lactic acid bacteria and bifidobacteria with potential to design natural biofunctional health-promoting dairy foods. Front Microbiol. 2017;8. https://doi.org/10.3389/fmicb.2017.00846.

21. Fazilah NF, Ariff AB, Khayat ME, Rios-Solis L, Halim M. Influence of probiotics, prebiotics, synbiotics and bioactive phytochemicals on the formulation of functional yogurt. J Funct Foods. 2018;48:387-99. https://doi.org/10.1016/j.jff.2018.07.039.

22. Rezac S, Kok CR, Heermann M, Hutkins R. Fermented foods as a dietary source of live organisms. Front Microbiol. 2018;9. https://doi. org/10.3389/fmicb.2018.01785.

23. Babio N, Becerra-Tomás N, Martínez-González MÁ, Corella D, Estruch R, Ros E, et al. Consumption of yogurt, low-fat milk, and other low-fat dairy products is associated with lower risk of metabolic syndrome incidence in an elderly Mediterranean population. J Nutr. 2015;145(10):2308-16. https://doi.org/10.3945/jn.115.214593.

24. Sayón-Orea C, Bes-Rastrollo M, Martí A, Pimenta AM, Martín-Calvo N, Martínez-González MA. Association between yogurt consumption and the risk of metabolic syndrome over 6 years in the SUN study. BMC Public Health. 2015;15:170. https://doi.org/10.1186/s12889-015-1518-7.

25. Madjd A, Taylor MA, Mousavi N, Delavari A, Malekzadeh R, Macdonald IA, et al. Comparison of the effect of daily consumption of probiotic compared with low-fat conventional yogurt on weight loss in healthy obese women following an energy-restricted diet: a randomized controlled trial. Am J Clin Nutr. 2016;103(2):323-9. https://doi. org/10.3945/ajcn.115.120170.

26. Mohammadi-Sartang M, Bellissimo N, Totosy de Zepetnek JO, Brett NR, Mazloomi SM, Fararouie M, et al. The effect of daily fortified yogurt consumption on weight loss in adults with metabolic syndrome: A 10-week randomized controlled trial. Nutr Metab Cardiovasc Dis. 2018;28(6):565-74. https://doi.org/10.1016/j.numecd.2018.03.001.

27. Wu L, Sun D. Consumption of yogurt and the incident risk of cardiovascular disease: A meta-analysis of nine cohort studies. Nutrients. 2017;9(3). https://doi.org/10.3390/nu9030315.

28. Zhang K, Chen X, Zhang L, Deng Z. Fermented dairy foods intake and risk of cardiovascular diseases: A meta-analysis of cohort studies. Crit Rev Food Sci Nutr. 2019;1-6. https://doi.org/10.1080/10408398.2 018.1564019.

29. Rizzoli R. Nutritional influence on bone: role of gut microbiota. Aging Clin Exp Res. 2019; 31(6):743-51. https://doi.org/10.1007/s40520-01901131-8.

30. Sahni S, Tucker KL, Kiel DP, Quach L, Casey VA, Hannan MT. Milk and yogurt consumption are linked with higher bone mineral density but not with hip fracture: the Framingham Offspring Study. Arch Osteoporos. 2013;8(0):119. https://doi.org/10.1007/s11657-013-0119-2.

31. Biver E, Durosier-Izart C, Merminod F, Chevalley T, van Rietbergen B, Ferrari SL, et al. Fermented dairy products consumption is associated with attenuated cortical bone loss independently of total calcium, protein, and energy intakes in healthy postmenopausal women. Osteoporos Int. 2018;29(8):1771-82. https://doi.org/10.1007/s00198018-4535-4.

32. Michaëlsson K, Wolk A, Lemming EW, Melhus H, Byberg L. Intake of milk or fermented milk combined with fruit and vegetable consumption in relation to hip fracture rates: A cohort study of Swedish Women. J Bone Miner Res. 2018;33(3):449-57. https://doi.org/10.1002/jbmr.3324.

33. Navarro-Alarcón M, Cabrera-Vique C, Ruiz-López MD, Olalla M, Artacho R, Giménez R, et al. Levels of Se, Zn, Mg and Ca in commercial goat and cow milk fermented products: Relationship with their chemical composition and probiotic starter culture. Food Chem. 2011;129(3):1126-31. https://doi.org/10.1016/j.foodchem.2011.05.090.

34. Quintana AV, Olalla-Herrera M, Ruiz-López MD, Moreno-Montoro M, Navarro-Alarcón M. Study of the effect of different fermenting microorganisms on the $\mathrm{Se}, \mathrm{Cu}, \mathrm{Cr}$, and $\mathrm{Mn}$ contents in fermented goat and cow milks. Food Chem. 2015;188:234-9. https://doi.org/10.1016/j. foodchem.2015.05.008.

35. Górska A, Przystupski D, Niemczura MJ, Kulbacka J. Probiotic Bacteria: A promising tool in cancer prevention and therapy. Curr Microbiol. 2019; 76(8):939-49. https://doi.org/10.1007/s00284-019-01679-8.

36. Pace F, Pace M, Quartarone G. Probiotics in digestive diseases: focus on Lactobacillus GG. Minerva Gastroenterol Dietol. 2015;61(4):273-92.

37. Faghfoori Z, Pourghassem Gargari B, Saber A, Seyyedi M, Fazelian S, Yari Khosroushahi A. Prophylactic effects of secretion metabolites of dairy lactobacilli through downregulation of ErbB-2 and ErbB-3 genes on colon cancer cells. Eur J Cancer Prev. 2017; https://doi.org/10.1097/ CEJ.0000000000000393.

38. Haghshenas B, Nami Y, Haghshenas M, Abdullah N, Rosli R, Radiah $\mathrm{D}$, et al. Bioactivity characterization of Lactobacillus strains isolated from dairy products. Microbiologyopen. 2015;4(5):803-13. https://doi. org/10.1002/mbo3.280.

39. Zhang K, Dai H, Liang W, Zhang L, Deng Z. Fermented dairy foods intake and risk of cancer. Int J Cancer. 2019;144(9):2099-108. https:// doi.org/10.1002/ijc.31959.

40. Guillemard E, Tondu F, Lacoin F, Schrezenmeir J. Consumption of a fermented dairy product containing the probiotic Lactobacillus casei $\mathrm{DN}-114001$ reduces the duration of respiratory infections in the elderly in a randomised controlled trial. Br J Nutr. 2010;103(1):58-68. https:// doi.org/10.1017/S0007114509991395.

41. Shadnoush M, Hosseini RS, Khalilnezhad A, Navai L, Goudarzi H, Vaezjalali M. Effects of probiotics on gut microbiota in patients with inflammatory bowel disease: A double-blind, placebo-controlled clinical trial. Korean J Gastroenterol. 2015;65(4):215-21. https://doi.org/10.4166/ kjg.2015.65.4.215.

42. Bolla PA, Carasi P, Serradell Mde L, De Antoni GL. Kefir-isolated Lactococcus lactis subsp. lactis inhibits the cytotoxic effect of Clostridium difficile in vitro. J Dairy Res. 2013;80(1):96-102. https:// doi.org/10.1017/S0022029912000623.

43. Agamennone V, Krul C AM, Rijkers G, Kort R. A practical guide for probiotics applied to the case of antibiotic-associated diarrhea in The Netherlands. BMC Gastroenterol. 2018;18(1):103. https://doi. org/10.1186/s12876-018-0831-x. 
44.Zhang B, Wang Y, Tan Z, Li Z, Jiao Z, Huang Q. Screening of probiotic activities of Lactobacilli strains isolated from traditional Tibetan qula, A raw yak milk cheese. Asian-Australas J Anim Sci. 2016;29(10):1490-9. https://doi.org/10.5713/ajas.15.0849.

45. Kołakowski P, Kowalska M, Sędrowska-Ćwiek J. Mikroflora serów dojrzewających. Innowacyjne Mleczarstwo. 2013;1(I):6-13.

46. Haghshenas B, Nami Y, Almasi A, Abdullah N, Radiah D, Rosli R, et al. Isolation and characterization of probiotics from dairies. Iran J Microbiol. 2017;9(4):234-43.

47. Cuffia F, Pavón Y, George G, Reinheimer J, Burns P. Effect of storage temperature on the chemical, microbiological, and sensory characteristics of pasta filata soft cheese containing probiotic lactobacilli. Food Sci Technol Int. 2019;1082013219854563. https:// doi.org/10.1177/1082013219854563.

48. Gagnaire V, Jardin J, Rabah H, Briard-Bion V, Jan G. Emmental cheese environment enhances Propionibacterium freudenreichii stress tolerance. PLoS ONE. 2015;10(8):e0135780. https://doi.org/10.1371/ journal.pone. 0135780 .

49. Rabah H, do Carmo FL, Jan G. Dairy Propionibacteria: Versatile probiotics. Microorganisms. 2017;5(2). https://doi.org/10.3390/ microorganisms5020024.

50. Hütt P, Songisepp E, Rätsep M, Mahlapuu R, Kilk K, Mikelsaar M. Impact of probiotic Lactobacillus plantarum TENSIA in different dairy products on anthropometric and blood biochemical indices of healthy adults. Benef Microbes. 2015;6(3):233-43. https:/doi.org/10.3920/ BM2014.0035

51. Lollo PCB, Morato PN, Moura CS, Almada CN, Felicio TL, Esmerino EA, et al. Hypertension parameters are attenuated by the continuous consumption of probiotic Minas cheese. Food Res Int. 2015;76(Pt 3):611-7. https://doi.org/10.1016/j.foodres.2015.07.015.

52. Tognon G, Nilsson LM, Shungin D, Lissner L, Jansson J-H, Renström F, et al. Nonfermented milk and other dairy products: associations with all-cause mortality. Am J Clin Nutr. 2017;105(6):1502-11. https://doi. org/10.3945/ajcn.116.140798.

53. Rizzoli R, Biver E. Effects of fermented milk products on bone. Calcif Tissue Int. 2018;102(4):489-500. https://doi.org/10.1007/s00223-0170317-9.

54. Sornplang P, Piyadeatsoontorn S. Probiotic isolates from unconventional sources: a review. J Anim Sci Technol. 2016;58:26. https://doi.org/10.1186/ s40781-016-0108-2.

55. Joishy TK, Dehingia M, Khan MR. Bacterial diversity and metabolite profiles of curd prepared by natural fermentation of raw milk and back sloping of boiled milk. World J Microbiol Biotechnol. 2019;35(7):102 https://doi.org/10.1007/s11274-019-2677-y.

56. Nadelman P, Magno MB, Masterson D, da Cruz AG, Maia LC. Are dairy products containing probiotics beneficial for oral health? A systematic review and meta-analysis. Clin Oral Investig. 2018;22(8):2763-85. https://doi.org/10.1007/s00784-018-2682-9.

57. Cicenia A, Scirocco A, Carabotti M, Pallotta L, Marignani M, Severi C. Postbiotic activities of Lactobacilli-derived factors. J Clin Gastroenterol. 2014;48:18-22. https://doi.org/10.1097/MCG.0000000000000231.

58. Cicenia A, Santangelo F, Gambardella L, Pallotta L, Iebba V, Scirocco A, et al. Protective role of postbiotic mediators secreted by Lactobacillus rhamnosus GG versus Lipopolysaccharide-induced damage in human colonic smooth muscle cells. J Clin Gastroenterol. 2016;50:140-4. https://doi.org/10.1097/MCG.0000000000000681.

59. Gao J, Li Y, Wan Y, Hu T, Liu L, Yang S, et al. A novel postbiotic from Lactobacillus rhamnosus GG with a beneficial effect on intestinal barrier function. Front Microbiol. 2019;10:477. https://doi.org/10.3389/ fmicb.2019.00477.

60.Han X, Lee A, Huang S, Gao J, Spence JR, Owyang C. Lactobacillus rhamnosus GG prevents epithelial barrier dysfunction induced by interferon-gamma and fecal supernatants from irritable bowel syndrome patients in human intestinal enteroids and colonoids. Gut Microbes. 2018;10(1):59-76. https://doi.org/10.1080/19490976.2018.1479625.

61. Compare D, Rocco A, Coccoli P, Angrisani D, Sgamato C, Iovine B, et al. Lactobacillus casei DG and its postbiotic reduce the inflammatory mucosal response: an ex-vivo organ culture model of post-infectious irritable bowel syndrome. BMC Gastroenterol. 2017;17. https://doi. org/10.1186/s12876-017-0605-x.

62. Tsilingiri K, Barbosa T, Penna G, Caprioli F, Sonzogni A, Viale G, et al. Probiotic and postbiotic activity in health and disease: comparison on a novel polarised ex-vivo organ culture model. Gut. 2012;61(7):1007-15. https://doi.org/10.1136/gutjnl-2011-300971.63.

63. Belizário JE, Faintuch J. Microbiome and gut dysbiosis. Exp Suppl. 2018;109:459-76. https://doi.org/10.1007/978-3-319-74932-7_13.

64. Carding S, Verbeke K, Vipond D, Corfe B, Owen L. Dysbiosis of the gut microbiota in disease. Microb Ecol Health and Dis. 2015;26. https://doi. org/10.3402/mehd.v26.26191.

65. Tojo R, Suárez A, Clemente MG, de los Reyes-Gavilán CG, Margolles A, Gueimonde $\mathrm{M}$, et al. Intestinal microbiota in health and disease: Role of bifidobacteria in gut homeostasis. World J Gastroenterol. 2014;20(41):15163-76. https://doi.org/10.3748/wjg.v20.i41.15163. 